\title{
A Case report: Importance of Molecular Allergy Diagnostics in Hen's Egg Allergy
}

\author{
Janne Burman*, Kati Palosuo and Anna Kaarina Kukkonen \\ Skin and Allergy Hospital, Finland
}

*Corresponding author: Janne Burman, Skin and Allergy Hospital, P.O. Box 160, 00029 HUS, Helsinki, Finland

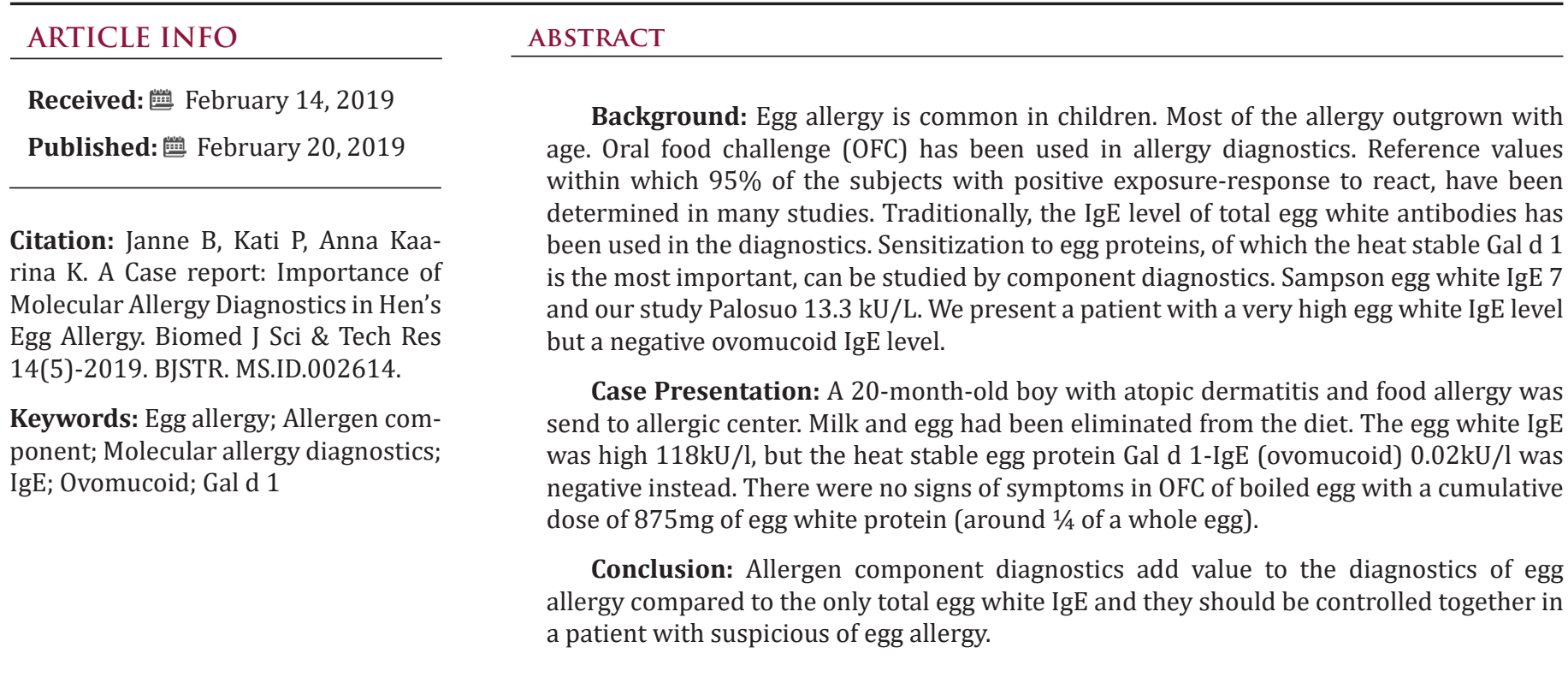

\section{Clinical Report}

\section{Background}

Hen's egg allergy is one of the most common allergies in children with prevalence of max 2,5\% of children [1]. The prognosis of outgrowth is excellent [1] and many children with egg allergy can tolerate boiled egg [2]. Allergen specific IgE predicts the probability of developing a reaction and can help to decide whether an oral food challenge should be performed [3]. Many studies have been determined to make $95 \%$ predictive decision points that vary in different populations [3]. The allergen characterized in egg white include Gal d 1 (ovomucoid), Gal d 2(ovalbumin), Gal d 3 (conalbumin and Gal d 4 (lysozyme) [4]. Gal d 1 remains soluble after heating, as Gal d 2, 3 and 4 are unstable proteins and heating and enzymatic digestion reduces their allergenicity $[4,5]$. We describe a patient with very high level of egg white IgE, and ovalbumin IgE but negative ovomucoid IgE. The patient passed an oral food challenge with a cumulative dose of $875 \mathrm{mg}$ of egg white protein.

\section{Case Presentation}

A 20-month-old child who was born full term by a cesarean section. The father of the child has atopic dermatitis and early childhood food allergies that outgrew with age. The mother had no history of atopy. The child developed severe atopic dermatitis beginning at the age of three months, which led to monitoring the child in the pediatric unit. The mother breastfed the child for 15 months and removed milk and eggs from her diet after which the condition of the skin seemed to improve. Finally, a calcineurin inhibitor treatment was started for atopic dermatitis after which the condition of the skin has remained good. At three months old, the laboratory findings were the following: egg white IgE was $51 \mathrm{kU} / \mathrm{l}$, milk IgE was $51 \mathrm{kU} / \mathrm{l}$, wheat $\operatorname{IgE}$ was $0.40 \mathrm{kU} / \mathrm{l}$. An accidental exposure to milk resulted in an urticarial reaction and vomiting. It was documented that the child didn't receive any egg. In laboratory testing, that the child underwent at the age of 20 months, the findings were for milk and egg (Table 1). The total 
egg white antibodies were very high, but the Gal d 1-antibodies (ovomucoid) were negative. An open 4-step food oral challenge with boiled hen's egg with a cumulative dose of $875 \mathrm{mg}$ egg white protein was performed in the patient. The exposure did not cause any symptoms and the child was in good condition after monitoring at discharge. If egg white IgE results alone had been used, would the exposure most likely have been left undone. Ovomucoid IgE added significant value to the case.

Table 1: Laboratory findings.

\begin{tabular}{|c|c|}
\hline Test & Value \\
\hline Blood Eosinophils & $5 \% / 0.53 \mathrm{E} 9 / \mathrm{l}$ \\
\hline Egg white IgE & $118 \mathrm{kU} / \mathrm{l}$ \\
\hline Gal d 1 IgE & $0.02 \mathrm{kU} / \mathrm{l}$ \\
\hline Gal d 2 IgE & $164 \mathrm{kU} / \mathrm{l}$ \\
\hline Gal d 3 IgE & $14.9 \mathrm{kU} / 1$ \\
\hline Gal d 4 IgE & $5.53 \mathrm{kU} / \mathrm{l}$ \\
\hline total IgE & $1121 \mathrm{kU} / \mathrm{l}$ \\
\hline
\end{tabular}

\section{Conclusion}

Component-resolved diagnostics add value in relation to the total antibody level in the study of egg allergy. It is possible that the patient can tolerate boiled egg in spite of a very high antibody level. In the case in question, the probability of allergy was extremely

ISSN: 2574-1241

DOI: 10.26717/BJSTR.2019.14.002614

Janne Burman. Biomed J Sci \& Tech Res

This work is licensed under Creative

Commons Attribution 4.0 License

Submission Link: https://biomedres.us/submit-manuscript.php high based on the egg white antibodies. However, ovomucoid IgE was low, which predicted tolerance to cooked egg. The patient was advised to avoid raw egg but introduce heated egg into the diet.

\section{Acknowledgments of Funding}

Jalmari and Rauha Ahokas foundation has supported the writing process. The corresponding author had final responsibility for the decision to submit for publication.

\section{References}

1. Nwaru BI, Hickstein L, Panesar SS, Roberts G, Muraro A, et al. (2014) Prevalence of common food allergies in Europe: a systematic review and meta-analysis. Allergy 69(8): 992-1007.

2. Clark A, Islam S, King Y, Deighton J, Szun S, et al. (2011) A longitudinal study of resolution of allergy to well-cooked and uncooked egg. Clin Exp Allergy 41(5): 706-712.

3. Calvani M, Arasi S, Bianchi A, Caimmi D, Cuomo B, et al. (2015) Is it possible to make a diagnosis of raw, heated, and baked egg allergy in children using cutoffs? A systematic review. Pediatr Allergy Immunol 26: 509-521.

4. Palosuo K, Kukkonen AK, Pelkonen AS, Mäkelä MJ (2018) Gal d 1-specific IgE predicts allergy to heated egg in Finnish children. Pediatr Allergy Immunol 29(6): 637-643.

5. Sampson HA (2001) Utility of food-specific IgE concentrations in predicting symptomatic food allergy. J Allergy Clin Immunol 107(5): 891-896.

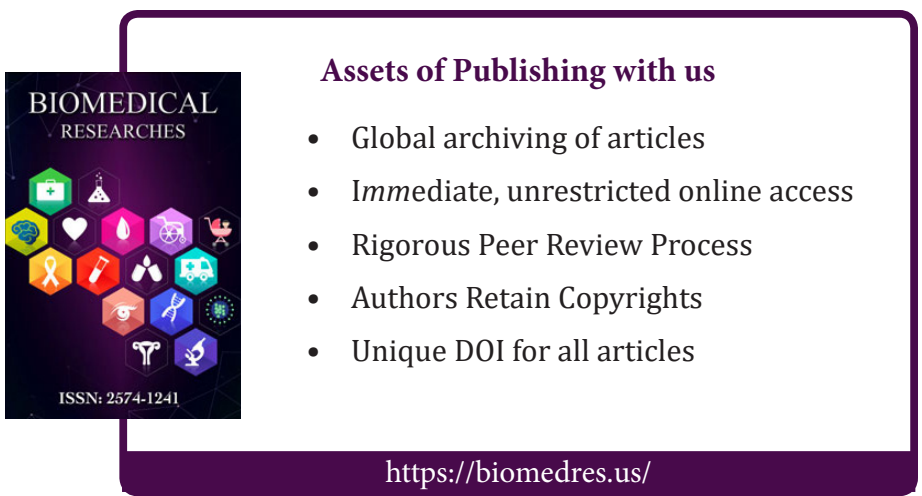

